submitted for examination by the State Department of Agriculture, were found infested by a Chermes which was provisionally determined as the above named species by both Dr. A. D. Hopkins of the U. S. Bureau of Entomology and the writer. This appears to be the first record of the introduction of this insect into America. It has been recorded by Gillanders as very destructive to young silver firs, comparatively young specimens of Abies nordmanniana and even fairly old trees of Abies nobilis. He states that young silver firs in nurseries are often killed outright by this insect. The data at hand justifies us in considering this species a dangerous form which should be excluded" if possible.

\title{
SOME RESULTS FROM FEEDING EGGS OF PORTHETRIA DISPAR TO BIRDS ${ }^{1}$
}

By C. W. Colniss, U. S. Dep't. of Agriculture, Bureau of Entomology, Melrose Highlands, Mass.

The question is ofttimes asked, "Do birds eat the eggs of the gipsy moth?" Several years ago Mr. E. H. Forbush stated that "No bird has actually been proved to feed upon the eggs except the English sparrow. One of these birds which was kept in confinement ate a few of the eggs from time to time when deprived of other food, but did not appear to relish them." 2 There is a possibility that some species may eat the eggs when other food becomes scarce. The latter often happens during the winter when Porthetria dispar eggs are found on trees, fences, stonewalls and in various other places for ten months of the year and may offer some temptation to birds at such critical times. The agents and inspectors engaged in gipsy moth work frequently report having seen egg clusters which have apparently been brolsen by birds.

At the suggestion of Mr. W. F. Fiske some experiments in feeding birds were conducted. Some English sparrows and a pigeon were secured. One of the purposes of the investigation was to determine the condition and vitality of the eggs after having passed through the digestive tract. The sparrow was chosen for the experiment mainly because it had been known to feed upon the eggs in confinement; the pigeon, merely to determine if the eggs would be digested. In all cases it was necessary to force the birds to eat them.

"Occasional contributions from the Gipsy Moth Parasite Laboratory, V.

'Mass. Board of Agriculture. "The Gypsy Moth." 1896, p. 231. 


\section{Experiment in Feeding English Sparrows}

The first lot of six sparrows was caught February 20. These were not offered food unfortunately until the following day, as the cage described later was being constructed. The hairy covering of the egg-cluster was removed by gently rubbing over cheesecloth, stretched between two boards. The eggs were mixed with dough made of cornmeal and water and used for food. The last of this lot of birds died during the night of February 21.

This proved an unsuccessful way of obliging the birds to eat the eggs. After a bolus of the food was forced into the beak, and the latter released in order that the bird might swallow, it would move the tongue to and fro, ejecting most of the eggs. No parts of eggs were found in the excrement or gizzard after the bird's death. This showed that none were swallowed by them while in captivity. Similar results were obtained from the second lot, which were captured March 6 , and which died on the evening of March 7 .

A different method was pursued in the latter experiments to compel the sparrows to swallow the eggs. They were inserted by means of a dampened toothpick, to which the eggs adhered. The toothpick was inserted well into the mouth and sometimes conveyed ten to fifteen of these, after which the sparrow was given a swallow of water. In this manner the birds were forced to swallow several eggs as is shown by the table.

One bird was captured. March 27 and died March 29; the other two April 10 and died April 11 and 12, respectively. In these experiments half-pound candy boxes were used, while the first two lots of birds were kept in a cage. It measured 8 inches square by 12 inches deep, with fly screen top and bottom. In one side a hole, large enough to admit the hand, was made and provided with a slide cover. By this arrangement it was possible to remove them conveniently at feeding time. It was decided that this cage was too large and allowed the birds too much freedom to fly, so that they killed themselves by constantly beating against the screens. The small candy boxes proved more satisfactory.

Approximately $356 P$. dispar eggs were fed to the last three sparrows. One hundred and forty-two of these eggs or 40 per cent. were found intact in the excrement. Seven of the 356 (2 per cent.) or 5 per cent. of the 142 that were passed intact hatched. One hundred and thirty-five or 38 per cent. was the approximate number found to be digested or partly so. Small pieces of chorion, which is indigestible, could usually be seen with the aid of a lens. Seventy-nine of the 

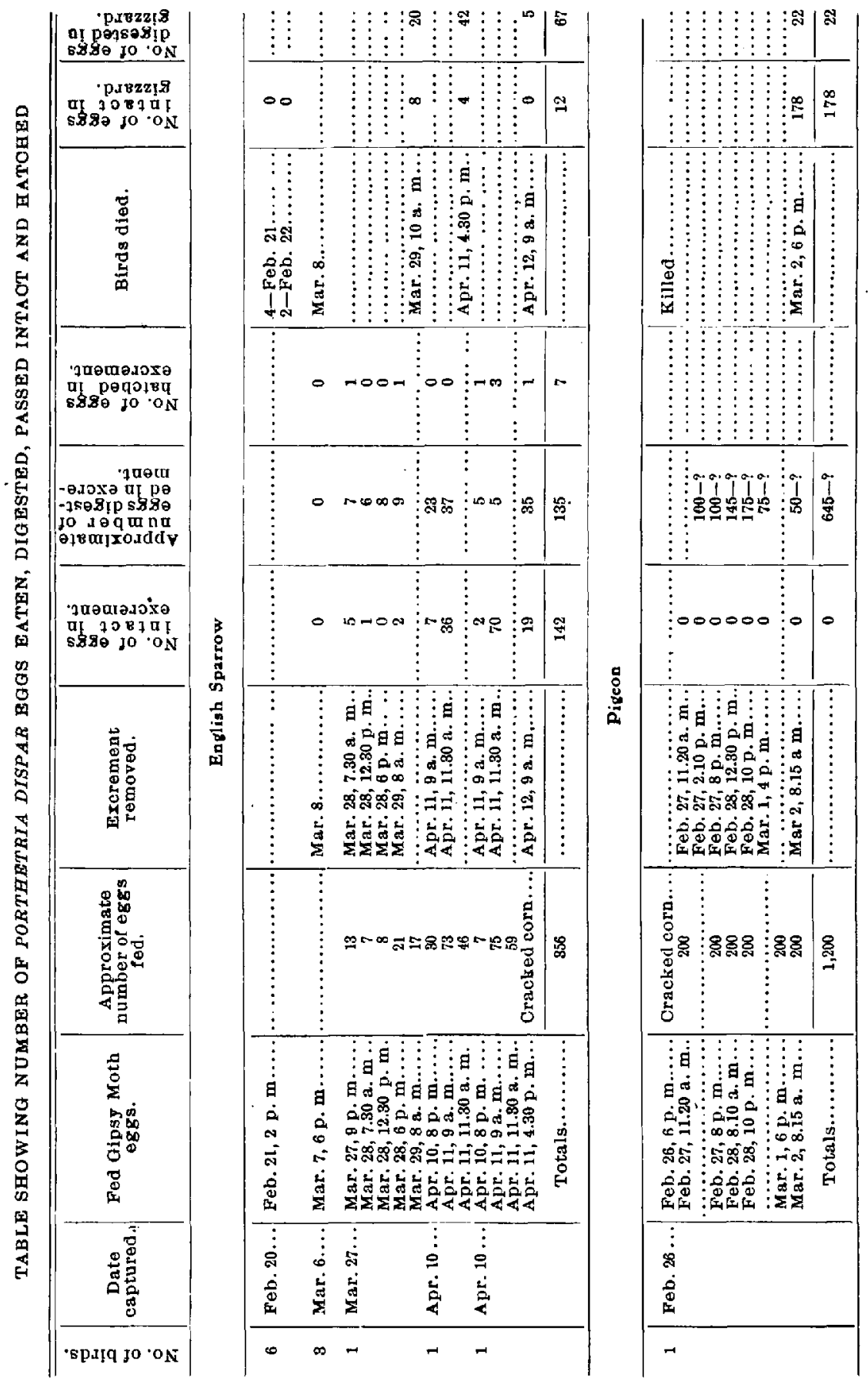
eggs or 22 per cent. still remained in the gizzard of the three sparrows after death. Twelve of these were intact, while the remainder consisted of various sized pieces of chorion.

Many of the eggs that were found whole in the excrement contained large wrinkles. This was undoubtedly the result of the grinding and pressure the eggs received while passing through the gizzard. This organ is very muscular and by its contraction and expansion, assisted by the gastric juices, has a tendency to crush all contents. Undoubtedly most of the 135 eggs passed intact, which did not hatch, were injured in passing through this organ.

\section{Experiment in Feeding a Pigeon}

A female pigeon was secured February 26 and encaged in a box $12 \times 12 \times 18$ inches. Cracked corn and dough containing $P$. dispar eggs were placed in the cage during the first day, but the pigeon did not partake of either. It appeared very lonely and inactive, which was perhaps due to being separated from its mate. As it did not tale food voluntarily, it was removed from the cage twice daily, and egg and dough mixture forced into the beal. About 200 eggs were given each time. The excrement was removed from the aage after each voidance, and carefully examined, yet it revealed no eggs intact. They were well ground in every case, leaving no parts distinguishable, save the small particles of chorion. The pigeon was fed for the last time at 8.15 a. m., March 2, and killed at $6 . \mathrm{p}$. m. of the same day. No excrement was found in the eage after the morning feeding. Three hundred and fifty-five eggs intact and some meal were found in the crop. One hundred and seventy-eight and fragments of 22 others were removed from the gizzard. This indicates the slowness and thoroughness with which the pigeon digests its food. The vitality of gypsy moth eggs is totally destroyed after having been subjected to such a grinding process.

In concluding, it must be borne in mind that these experiments were conducted under abnormal conditions. The birds were not only forced to swallow the food, but were deprived of their freedom, which is essential to rapid and vigorous digestion. To procure the data obtained would have been difficult in the field, as it would have necessitated long and careful watches and the killing of many useful species. It would have been impossible to find the voided excrements desirable. However, there remains a field open to investigation for accurate notes on species of birds liable to eat the eggs of $P$. dispar, and the condition of the latter when recovered in the excrement under normal conditions. 